\title{
Interactions between worms and malaria: Good worms or bad worms?
}

Mathieu Nacher ${ }^{1,2,3}$

\begin{abstract}
In the past decade there have been an increasing number of studies on co-infections between worms and malaria. However, this increased interest has yielded results that have been at times conflicting and made it difficult to clearly grasp the outcome of this interaction. Despite the heterogeneity of study designs, reviewing the growing body of research may be synthesized into some broad trends: Ascaris emerges mostly as protective from malaria and its severe manifestations, whereas hookworm seems to increase malaria incidence. As efforts are made to de-worm populations in malaria endemic areas, there is still no clear picture of the impact these programmes have in terms of quantitative and qualitative changes in malaria.
\end{abstract}

\section{Background}

In 1977, it was reported that malnourished patients heavily infected with Ascaris lumbricoides were free of malaria [1]. In 1978, the same team reported that piperazine treatment of patients with a heavy worm burden of Ascaris was followed by an increase in malaria attacks [2]. For the following 20 years, there were no other studies on the subject, perhaps for lack of connections between the fields of nutrition and malaria epidemiology or immunology. In the past decade, the topic was rediscovered, this time from an immunological angle. Depending on which publication one reads, it is not clear if the outcome of this interaction is beneficial [3], neutral [4] or harmful [5]. The studies on the interactions between worms and malaria in humans have been very different in design, in the age groups sampled, in the way the malaria outcome and the exposure to helminths were considered. It is, therefore, impossible to conduct a meta-analysis to settle the matter. Despite these difficulties, the present review aims to synthesize the growing number of studies that have explored the interactions between worms and malaria. Pubmed and google scholar searches were performed for malaria and any of the keywords worms, helminth, Ascaris, hookworm, Trichuris, or Strongyloides. This search identified

\footnotetext{
Correspondence: mathieu.nacher@ch-cayenne.fr

${ }^{1}$ Centre d'investigation Clinique épidémiologie Clinique Antilles-Guyane, CIC

EC Inserm CIE 802, Centre Hospitalier de Cayenne, French Guiana

Full list of author information is available at the end of the article
}

published papers which were then studied for additional references.

\section{Studies in humans (Additional File 1, Table S1) \\ Ascaris lumbricoides and malaria}

When it comes to coinfections between worms and malaria, Ascaris lumbricoides has been the most cited worm. Eight studies found that Ascaris was associated with a reduction of malaria (incidence, prevalence or reduction of parasitemia)[1,2,6-11], two studies found that Ascaris was associated with an increase in malaria prevalence $[12,13]$, and two studies found no relation to malaria $[4,14]$. For cerebral malaria or renal failure, two studies identified Ascaris lumbricoides as the only individual worm associated with protection from severe malaria in adults $[3,15]$. One study observed an increase of severe malaria in Ascaris-infected children [16]. This study is often cited as an example that worms are bad for malaria, but the use of vomiting - which can be caused by Ascaris- as a definition criteria of severe malaria is problematic [17]. To summarize in even broader strokes, for Ascaris, 10 studies observed protection from malaria, three found an increase of malaria and two found no association at all with malaria. Another approach to the question compiled national ecologic data on worm prevalence, malaria incidence, climate, and GDP per capita, showed a ten-fold increase in malaria incidence in equatorial climates, low GDP, and Ascaris lumbricoides prevalence $<25 \%$ relative to prevalence $\geq 25 \%$ (submitted).
C Biomed Central

() 2011 Nacher; licensee BioMed Central Ltd. This is an Open Access article distributed under the terms of the Creative Commons Attribution License (http://creativecommons.org/licenses/by/2.0), which permits unrestricted use, distribution, and reproduction in any medium, provided the original work is properly cited. 


\section{Hookworm and malaria}

Hookworms seem to be associated with more malaria. There is a marked spatial overlap between hookworm infections and malaria in Africa [18]. Hookworm is the second most common GI nematode reported to have interactions with malaria. Although there was an apparent potentiation of the protection associated with Ascaris [3], results often differ from those of co-infections with Ascaris lumbricoides. Seven field studies, and one regression trees analysis of ecological data, finding increased malaria $[9,11,12,15,19-21]$, whereas one study did not find any association between hookworms and malaria [4].

\section{Pooled GI nematodes and malaria}

Because of the assumption that the immune response to different helminths has a "stereotypical" profile, some studies pooled GI nematodes together. An increase in incidence was observed in three studies [22-24], a decrease in prevalence was observed in 1 study [25], and no association was observed with malaria in three studies $[4,14,26]$. Regarding malaria severity, three studies observed that GI nematodes were associated with protection from severe malaria $[9,27,28]$. The association between GI nematodes and protection from severe malaria remained after controlling for socioeconomic and environmental factors [29], and nutritional indicators. The quantification worm burden was proportionally associated with the level of protection from severe malaria, and the number of different GI nematodes present was both proportionally associated with protection from severe malaria [27] and increased incidence [22].

\section{Schistosomiasis and malaria}

There again four studies found different results. One study on Schistosoma mansoni found increased falciparum malaria incidence [30], whereas two studies on Schistosoma haematobium found protection from malaria: significantly lower parasitaemia, and lower incidence, although not significantly for the first [26], and decreased incidence in the second study [31], and one found no significant difference [32].

Prevalence is determined by the combination of incidence and infection duration. In clinical cases of malaria, treatment usually interrupts the natural course of the infection. The influence of helminths on the duration of a malaria episode in humans is not known. However, they seem to reduce some symptoms of malaria that can lead patients to seek treatment [33]. This may thus increase the overall duration of the presence of detectable malaria parasites in the bloodstream and potentially increase prevalence. But an increase in prevalence can also be due to increased incidence. Although it is not always clear in the publications whether incidence or prevalence is reported, overall five studies observed increased incidence in those with helminths, three observed decreased incidence and two found no difference. For prevalence, six studies found an increase in patients with intestinal worms, three found a decrease, and one found no difference. When looking at which worms are predominantly involved in these observations hookworm was associated with increased malaria incidence in two studies, and increased prevalence in five studies; in contrast Ascaris was reported to be associated with decreased incidence in two studies, and with decreased prevalence in three studies; one study found increased malaria incidence and another finds increased malaria prevalence in Ascaris-infected persons. Overall, there are thus some striking differences between Ascaris lumbricoides and hookworm. Whether these differences are only due to immunological factors, or if, as hypothesized elsewhere, hookworm-related anaemia leads to increased attractiveness for the vector [15] remains to be demonstrated. The findings in adults cannot easily be extrapolated to children $<5$ years of age. Some studies suggest important age-related differences [6,32], whereas others show results that seem to mirror the results from adult studies [9].

Apart from variations of incidence or severity, gastrointestinal nematodes have also been related to malaria in intriguing ways that raise important evolutionary questions, however, the increase of gametocyte carriage in nematode-infected patients [34], the increased multiplicity of infection $[35,36]$, and the relation between Ascaris fecundity and fever [37] first need confirmation [15].

Most studies involved Plasmodium falciparum, but a protective effect from Plasmodium vivax malaria was also observed in three studies $[2,10,11]$.

\section{Hypothetical immunological mechanisms}

Worms have different life histories but they bias the immune responses towards a stereotypical TH2/Treg response [38]. Malaria immunity has been studied extensively but it is still incompletely understood [39]. The balance between the pro and anti-inflammatory cytokines seems central in the pathogenesis of severe malaria, but helminth infections, a major reality in the tropics, are rarely considered when immunity to malaria is discussed. Chronic helminth immune modulation towards TH2/Treg lymphocytes would therefore be presumed to modify a number of aspects of malaria immunity. But knowledge on this is still very sketchy, to say the least. One of the specific hypotheses for the association of worms with protection from severe malaria was that worms led to an increase in IgE complexes that activated the FCERII (CD23) and thereby releases the anti-inflammatory IL10 and activated the inducible Nitric oxide synthase, which led to the release of nitric oxide, and reduced sequestration of parasitized red 
blood cells [40]. Another potential explanation for the observed interactions is that $\mathrm{T}$ cells with a regulatory function may be preferably induced in helminth-infected patients thereby leading to a suppression of TH1 cells and proinflammatory activity [41,42].

Another hypothesis is that worms decrease cytophilic IgG1 and IgG3 antibodies whereas it increased the noncytophilic IgG2, IgG4, IgM antibodies, and that this altered antibody-dependent cellular inhibition (ADCI). This hypothesis leads to different predictions with both an increase in incidence and severity [5,43]. Although so far the findings seem to fit with the initial hypothesis, it does not prove that the reason why malaria incidence increased was the shift towards non-cytophilic immunoglobulins. The above hypotheses explore different aspects of the immune response and do not exclude one another.

\section{Same, but different}

All studies on worms and their effect on the immune response against malaria parasites have pooled different worm species into one single variable. This was based on the premise that worms induce similar immune responses and the fact that sample sizes in these studies were too small for a detailed analysis of each worm species' individual effect. The epidemiological studies, however, seem to suggest that there are differences between the different GI nematodes. Ascaris lumbricoides seems to be singled out when the outcome is "less malaria", whereas hookworm seemed more frequently involved when increased incidence is studied. Ascaris lumbricoides lays more eggs and it is arguable that this may make it easier to detect. However, if immunity alone is considered, A. lumbricoides is the largest nematode and the weight of foreign biological material involved in a host is arguably larger than for any other parasite. Moreover, in laboratories around the world Ascaris antigens are notoriously potent allergens. A large field study comparing IgE concentrations between different GI nematodes showed that total IgE levels were highest in Ascaris-infected children [44]. The reason why this parasite would evolve to stimulate such intense reactions may be related to the potential acuteness of the surgical complications of $A$. lumbricoides and the adaptiveness of generating immune responses limiting superinfection. This would fit with the IgE CD23/NO hypothesis discussed above, and possibly with the Treg hypothesis. Although some GI nematodes lead to a skew towards non cytophilic antibodies, a study seemed to show that Ascaris-infected persons had higher total IgG1 and IgG3 concentrations [45].

The hypothetical mechanisms for the apparent singular increase of malaria in hookworm infections could be linked to the combination of immune modulation and hookworm-related blood loss, which could, depending on the level of anemia, increase cues that are attractive for the vector (lactates, increased respiratory frequency and $\mathrm{CO} 2$ exhalation, increased cardiac output) thus leading to a greater probability of infective bites [15]. In this perspective, the hookworm vaccine initiative could have a interesting double impact: protection from hookworm's direct morbidity and maybe it's impact on malaria incidence.

\section{Animal models}

Animal models have been use to explore co-infections between different helminths and malaria parasites before the first studies in humans [46]. Additional File 2, Table S2 summarizes the various experiments that have been conducted since then. The malaria outcomes of the interaction range from protection (13 studies) to increased severity (eight studies), while other models found no effect ( 5 studies). It is difficult to get a simple general idea of the outcome of the different coinfections. It should be emphasized that these models are not natural infections and therefore natural selection has not operated on outcome of repeated interactions. In addition, the extrapolation of findings on murine cerebral malaria to human cerebral malaria is questionable [47]. The insights gained from the models thus seem difficult to apply to humans.

\section{Conclusions}

The default condition of the mammalian ancestral immune system was to be parasitized by gastrointestinal nematodes and other helminths, and acute responses to microparasites were tuned to this TH2/Treg skew. Researchers have long been unaware of the fact that worms significantly impact malaria, the strongest known selective force on the human genome. Despite a growing number of studies, and some emerging patterns, there is still scarce data on the immunological consequences of worms-malaria co-infections and the precise mechanisms at play. Nevertheless, vaccine trials and vaccination campaigns in the tropics should definitely take worms into account [48].

More research is needed to disentangle the underlying immunological mechanisms, the differences between different helminths, and the effect of age on the outcome of co-infections. The present review can cautiously conclude that worms, notably Ascaris, are associated with protection from severe complications and that they can, notably hookworm, lead to increased malaria incidence or prevalence. Thus, although it is tempting to rush to the conclusion that de-worming patients would reduce malaria, it still seems wise to be attentive to the potential scenario of an increase of severe malaria. Monitoring the incidence of malaria and severe malaria before and 
after vertical de-worming campaigns seems a minimum test to make sure there is a better understanding of what is going on at a population level, and that, for individual patients, it is best to follow the medical precept primum non nocere - first do no harm.

\section{Additional material}

Additional file 1: Table S1: Studies on the interactions between worms and malaria in Humans [49].

Additional file 2: Table S2. Animal models of coinfection between worms and malaria [50-72].

\section{Author details}

${ }^{1}$ Centre d'investigation Clinique épidémiologie Clinique Antilles-Guyane, ClC EC Inserm CIE 802, Centre Hospitalier de Cayenne, French Guiana. ${ }^{2}$ Equipe EA 35 93, Epidémiologie des parasitoses et mycoses tropicales, Université Antille-Guyane, Campus Saint Denis, Cayenne, French Guiana. ${ }^{3}$ Department of Tropical Medicine, School of Public Health and Tropical Medicine, Tulane University, New Orleans, USA.

\section{Competing interests}

The authors declare that they have no competing interests.

Received: 3 March 2011 Accepted: 12 September 2011 Published: 12 September 2011

\section{References}

1. Murray MJ, Murray AB, Murray MB, Murray CJ: Parotid enlargement, forehead edema, and suppression of malaria as nutritional consequences of ascariasis. Am J Clin Nutr 1977, 30:2117-2121.

2. Murray J, Murray A, Murray M, Murray C: The biological suppression of malaria: an ecological and nutritional interrelationship of a host and two parasites. Am J Clin Nutr 1978, 3:1363-1366.

3. Nacher M, Gay F, Singhasivanon P, Krudsood S, Treeprasertsuk S, Mazier D, Vouldoukis I, Looareesuwan S: Ascaris lumbricoides infection is associated with protection from cerebral malaria. Parasite Immunol 2000, 22:107-113.

4. Shapiro AE, Tukahebwa EM, Kasten J, Clarke SE, Magnussen P, Olsen A, Kabatereine NB, Ndyomugyenyi R, Brooker S: Epidemiology of helminth infections and their relationship to clinical malaria in southwest Uganda. Trans R Soc Trop Med Hyg 2005, 99:18-24.

5. Druilhe $P$, Tall A, Sokhna C: Worms can worsen malaria: towards a new means to roll back malaria? Trends Parasitol 2005, 21:359-362.

6. Brutus L, Watier L, Briand V, Hanitrasoamampionona V, Razanatsoarilala H, Cot M: Parasitic co-infections: does Ascaris lumbricoides protect against Plasmodium falciparum infection? Am J Trop Med Hyg 2006, 75:194-198.

7. Brutus L, Watier L, Hanitrasoamampionona V, Razanatsoarilala H, Cot M: Confirmation of the protective effect of Ascaris lumbricoides on Plasmodium falciparum infection: results of a randomized trial in Madagascar. Am J Trop Med Hyg 2007, 77:1091-1095.

8. Van Eijk AM, Lindblade KA, Odhiambo F, Peterson E, Rosen DH, Karanja D, Ayisi JG, Shi YP, Adazu K, Slutsker L: Geohelminth Infections among pregnant women in rural western Kenya; a cross-sectional study. PLOS Negl Trop Dis 2009, 3:e370.

9. Degarege A, Animut A, Legesse M, Erko B: Malaria severity status in patients with soil-transmitted helminth infections. Acta Trop 2009, 112:8-11.

10. Melo GC, Reyes-Lecca RC, Vitor-Silva S, Monteiro WM, Martins M, Benzecry SG, Alecrim MG, Lacerda MV: Concurrent helminthic infection protects schoolchildren with Plasmodium vivax from anemia. PLoS One 5:e11206.

11. Boel M, Carrara V, Rijken M, Proux S, Nacher M, Pimanpanarak M, Paw MK, Moo O, Gay H, Bailey W, et al: Complex Interactions between Soiltransmitted Helminths and Malaria in Pregnant Women on the ThaiBurmese Border. Plos Neglected Tropical Diseases 2010.
12. Yatich NJ, Yi J, Agbenyega T, Turpin A, Rayner JC, Stiles JK, Ellis WO, Funkhouser E, Ehiri JE, Williams JH, et al: Malaria and intestinal helminth co-infection among pregnant women in Ghana: prevalence and risk factors. Am J Trop Med Hyg 2009, 80:896-901.

13. Adegnika AA, Ramharter M, Agnandji ST, Ateba Ngoa U, Issifou S, Yazdanbahksh M, Kremsner PG: Epidemiology of parasitic co-infections during pregnancy in Lambarene, Gabon. Trop Med Int Health 15:1204-1209.

14. Bejon P, Mwangi TW, Lowe B, Peshu N, Hill AV, Marsh K: Helminth infection and eosinophilia and the risk of Plasmodium falciparum malaria in 1- to 6-year-old children in a malaria endemic area. PLoS Negl Trop Dis 2008, 2:e164.

15. Nacher M: Worms and malaria: blind men feeling the elephant? Parasitology 2008, 135:861-868.

16. Le Hesran JY, Akiana J, Ndiaye el HM, Dia M, Senghor P, Konate L: Severe malaria attack is associated with high prevalence of Ascaris lumbricoides infection among children in rural Senegal. Trans $R$ Soc Trop Med Hyg 2004, 98:397-399.

17. Nacher M: Comment on: Severe malaria attack is associated with high prevalence of Ascaris lumbricoides infection among children in rural Senegal. Trans R Soc Trop Med Hyg 2005, 99:161-163, discussion 164-165.

18. Brooker S, Clements AC, Hotez PJ, Hay SI, Tatem AJ, Bundy DA, Snow RW: The co-distribution of Plasmodium falciparum and hookworm among African schoolchildren. Malar J 2006, 5:99.

19. Hillier SD, Booth M, Muhangi L, Nkurunziza P, Khihembo M, Kakande M, Sewankambo M, Kizindo R, Kizza M, Muwanga M, et al: Plasmodium falciparum and helminth coinfection in a semi urban population of pregnant women in Uganda. J Infect Dis 2008, 198:920-927.

20. Midzi N, Sangweme D, Zinyowera S, Mapingure MP, Brouwer KC, Munatsi A, Mutapi F, Mudzori J, Kumar N, Woelk G, et al: The burden of polyparasitism among primary schoolchildren in rural and farming areas in Zimbabwe. Trans R Soc Trop Med Hyg 2008, 102:1039-1045.

21. Pullan RL, Kabatereine NB, Bukirwa H, Staedke SG, Brooker S: Heterogeneities and consequences of Plasmodium species and hookworm coinfection: a population based study in Uganda. J Infect Dis 2011, 203:406-417.

22. Nacher $M$, Singhasivanon $P$, Yimsamran S, Manibunyong $W$ Thanyavanich N, Wuthisen R, Looareesuwan S: Intestinal helminth infections are associated with increased incidence of Plasmodium falciparum malaria in Thailand. J Parasitol 2002, 88:55-58.

23. Spiegel A, Tall A, Raphenon G, Trape JF, Druilhe P: Increased frequency of malaria attacks in subjects co-infected by intestinal worms and Plasmodium falciparum malaria. Trans R Soc Trop Med Hyg 2003 97:198-199.

24. Kirwan P, Jackson AL, Asaolu SO, Molloy SF, Abiona TC, Bruce MC, RanfordCartwright L, O'Neill SM, Holland CV: Impact of repeated four-monthly anthelmintic treatment on Plasmodium infection in preschool children: a double-blind placebo-controlled randomized trial. BMC Infect Dis $10: 277$.

25. Kung'U JK, Goodman D, Haji HJ, Ramsan M, Wright VJ, Bickle QD Tielsch JM, Raynes JG, Stoltzfus RJ: Early helminth infections are inversely related to anemia, malnutrition, and malaria and are not associated with inflammation in 6- to 23-month-old Zanzibari children. Am J Trop Med Hyg 2009, 81:1062-1070.

26. Briand V, Watier L, JY LEH, Garcia A, Cot M: Coinfection with Plasmodium falciparum and schistosoma haematobium: protective effect of schistosomiasis on malaria in senegalese children? Am J Trop Med Hyg 2005, 72:702-707.

27. Nacher M, Singhasivanon P, Traore B, Vannaphan S, Gay F, Chindanond D, Franetich JF, Mazier D, Looareesuwan S: Helminth infections are associated with protection from cerebral malaria and increased nitrogen derivatives concentrations in Thailand. Am J Trop Med Hyg 2002, 66:304-309.

28. Nacher M, Singhasivanon P, Silachamroon U, Treeprasertsuk S, Vannaphan S, Traore B, Gay F, Looareesuwan S: Helminth infections are associated with protection from malaria-related acute renal failure and jaundice in Thailand. Am J Trop Med Hyg 2001, 65:834-836.

29. Nacher M, Singhasivanon P, Vannaphan S, Treeprasertsuk S, Phanumaphorn M, Traore B, Looareesuwan S, Gay F: Socio-economic and environmental protective/risk factors for severe malaria in Thailand. Acta Trop 2001, 78:139-146. 
30. Sokhna C, Le Hesran JY, Mbaye PA, Akiana J, Camara P, Diop M, Ly A, Druilhe $P$ : Increase of malaria attacks among children presenting concomitant infection by Schistosoma mansoni in Senegal. Malar J 2004, 3:43.

31. Lyke KE, Dicko A, Dabo A, Sangare L, Kone A, Coulibaly D, Guindo A, Traore K, Daou M, Diarra I, et al: Association of Schistosoma haematobium infection with protection against acute Plasmodium falciparum malaria in Malian children. Am J Trop Med Hyg 2005, 73:1124-1130

32. Diallo TO, Remoue F, Schacht AM, Charrier N, Dompnier JP, Pillet S, Garraud O, N'Diaye AA, Capron A, Capron M, et al: Schistosomiasis coinfection in humans influences inflammatory markers in uncomplicated Plasmodium falciparum malaria. Parasite Immunol 2004, 26:365-369.

33. Nacher M, Singhasivanon P, Traore B, Dejvorakul S, Phumratanaprapin W, Looareesuwan S, Gay F: Short report: Hookworm infection is associated with decreased body temperature during mild Plasmodium falciparum malaria. Am J Trop Med Hyg 2001, 65:136-137.

34. Nacher M, Singhasivanon P, Silachamroon U, Treeprasertsu S, Krudsood S, Gay F, Mazier D, Looareesuwan S: Association of helminth infections with increased gametocyte carriage during mild falciparum malaria in Thailand. Am J Trop Med Hyg 2001, 65:644-647.

35. Chaorattanakawee S, Natalang O, Hananantachai H, Nacher M, Brockman A, Nosten F, Looareesuwan S, Patarapotikul J: Trichuris trichiura infection is associated with the multiplicity of Plasmodium falciparum infections, in Thailand. Ann Trop Med Parasitol 2003, 97:199-202

36. Nacher M, Singhasivanon P, Gay F, Silachomroon U, Phumratanaprapin W, Looareesuwan S: Contemporaneous and successive mixed Plasmodium falciparum and Plasmodium vivax infections are associated with Ascaris lumbricoides: an immunomodulating effect? J Parasitol 2001, 87:912-915.

37. Nacher M, Singhasivanon P, Krudsood S, Phumratanaprapin W, Vanaphan S, Tangpukdee N, Carme B, Looareesuwan S: Inverse relationship between the number of fertilized Ascaris eggs excreted and fever, in patients coinfected with Plasmodium vivax and Ascaris lumbricoides. Ann Trop Med Parasitol 2005, 99:623-625.

38. Jackson JA, Friberg IM, Little S, Bradley JE: Review series on helminths, immune modulation and the hygiene hypothesis: immunity against helminths and immunological phenomena in modern human populations: coevolutionary legacies? Immunology 2009, 126:18-27.

39. Langhorne J, Ndungu FM, Sponaas AM, Marsh K: Immunity to malaria: more questions than answers. Nat Immunol 2008, 9:725-732.

40. Nacher M: Worms and malaria: noisy nuisances and silent benefits. Parasite Immunol 2002, 24:391-393.

41. Hartgers FC, Obeng BB, Kruize YC, Dijkhuis A, McCall M, Sauerwein RW, Luty AJ, Boakye DA, Yazdanbakhsh M: Responses to malarial antigens are altered in helminth-infected children. J Infect Dis 2009, 199:1528-1535.

42. Wammes LJ, Hamid F, Wiria AE, de Gier B, Sartono E, Maizels RM, Luty AJ, Fillie $Y$, Brice GT, Supali T, et al: Regulatory $T$ cells in human geohelminth infection suppress immune responses to BCG and Plasmodium falciparum. Eur J Immunol 40:437-442

43. Roussilhon $C$, Brasseur $P$, Agnamey $P$, Perignon $J$, Druilhe $P$ : Understanding human-Plasmodium falciparum immune interactions uncovers the immunological role of worms. PLoS One 5:e9309.

44. Johansson SG, Mellbin T, Vahlquist B: Immunoglobulin levels in Ethiopian preschool children with special reference to high concentrations of immunoglobulin E (IgND). Lancet 1968, 1:1118-1121.

45. McSharry C, Xia Y, Holland CV, Kennedy MW: Natural immunity to Ascaris lumbricoides associated with immunoglobulin $E$ antibody to $A B A-1$ allergen and inflammation indicators in children. Infect Immun 1999, 67:484-489.

46. Lewinsohn R: Anaemia in mice with concomitant Schistosoma mansoni and Plasmodium berghei yoelii infection. Trans R Soc Trop Med Hyg 1975, 69:51-56.

47. White NJ, Turner GD, Medana IM, Dondorp AM, Day NP: The murine cerebral malaria phenomenon. Trends Parasitol 26:11-15.

48. Nacher M: Malaria vaccine trials in a wormy world. Trends Parasitol 2001, 17:563-565.

49. Nacher M, Singhasivanon $P$, Gay F, Phumratanaprapin W, Silachamroon U, Looareesuwan S: Association of helminth infection with decreased reticulocyte counts and hemoglobin concentration in Thai falciparum malaria. Am J Trop Med Hyg 2001, 65:335-337.
50. Tetsutani K, Ishiwata K, Ishida H, Tu L, Torii M, Hamano S, Himeno K, Hisaeda $\mathrm{H}$ : Concurrent infection with Heligmosomoides polygyrus suppresses anti-Plasmodium yoelii protection partially by induction of CD4(+)CD25(+)Foxp3(+) Treg in mice. Eur J Immunol 2009, 39:2822-2830.

51. Segura M, Matte C, Thawani N, Su Z, Stevenson MM: Modulation of malaria-induced immunopathology by concurrent gastrointestinal nematode infection in mice. Int J Parasitol 2009, 39:1525-1532.

52. Tetsutani K, Ishiwata K, Torii M, Hamano S, Hisaeda H, Himeno K: Concurrent infection with Heligmosomoides polygyrus modulates murine host response against Plasmodium berghei ANKA infection. Am J Trop Med Hyg 2008, 79:819-822.

53. De Souza B, Helmby H: Concurrent gastro-intestinal nematode infection does not alter the development of experimental cerebral malaria. Microbes Infect 2008, 10:916-921.

54. Su Z, Segura M, Morgan K, Loredo-Osti JC, Stevenson MM: Impairment of protective immunity to blood-stage malaria by concurrent nematode infection. Infect Immun 2005, 73:3531-3539.

55. Noland GS, Urban JF Jr, Fried B, Kumar N: Counter-regulatory anti-parasite cytokine responses during concurrent Plasmodium yoelii and intestinal helminth infections in mice. Exp Parasitol 2008, 119:272-278.

56. Noland GS, Chowdhury DR, Urban JF Jr, Zavala F, Kumar N: Helminth infection impairs the immunogenicity of a Plasmodium falciparum DNA vaccine, but not irradiated sporozoites, in mice. Vaccine 28:2917-2923.

57. Su Z, Segura M, Stevenson MM: Reduced protective efficacy of a bloodstage malaria vaccine by concurrent nematode infection. Infect Immun 2006, 74:2138-2144.

58. Helmby $\mathrm{H}$ : Gastrointestinal nematode infection exacerbates malariainduced liver pathology. J Immunol 2009, 182:5663-5671.

59. Ngwenya BZ: Enhanced resistance to Plasmodium berghei in mice previously infected with Trichinella spiralis. Parasite Immunol 1982, 4:197-207.

60. Bailenger J, Lucchese F, Peychaud A, Haumont G, Cabannes A: [Inhibition of Plasmodium berghei in rats infested with Strongyloides ratti or Trichinella spiralis; role of high blood corticosterone in reaction to the development of helminths]. Ann Parasitol Hum Comp 1985, 60:435-443.

61. Xiao N, Furuta T, Kiguchi T, Kojima S: [Effect of Nippostrongylus brasiliensis induced alterations in T helper cell subsets on Plasmodium berghei infection in mice]. Zhongguo Ji Sheng Chong Xue Yu Ji Sheng Chong Bing Za Zhi 2000, 18:286-290.

62. Christensen NO, Furu P, Kurtzhals J, Odaibo A: Heterologous synergistic interactions in concurrent experimental infection in the mouse with Schistosoma mansoni, Echinostoma revolutum, Plasmodium yoelii, Babesia microti, and Trypanosoma brucei. Parasitol Res 1988, 74:544-551.

63. Lwin M, Last C, Targett GA, Doenhoff MJ: Infection of mice concurrently with Schistosoma mansoni and rodent malarias: contrasting effects of patent S. mansoni infections on Plasmodium chabaudi, P. yoelii and P. berghei. Ann Trop Med Parasitol 1982, 76:265-273.

64. Laranjeiras RF, Brant LC, Lima AC, Coelho PM, Braga EM: Reduced protective effect of Plasmodium berghei immunization by concurrent Schistosoma mansoni infection. Mem Inst Oswaldo Cruz 2008, 103:674-677.

65. Legesse M, Erko B, Balcha F: Increased parasitaemia and delayed parasite clearance in Schistosoma mansoni and Plasmodium berghei co-infected mice. Acta Trop 2004, 91:161-166.

66. Yoshida A, Maruyama H, Kumagai T, Amano T, Kobayashi F, Zhang M, Himeno K, Ohta N: Schistosoma mansoni infection cancels the susceptibility to Plasmodium chabaudi through induction of type 1 immune responses in A/J mice. Int Immunol 2000, 12:1117-1125.

67. Noland GS, Graczyk TK, Fried B, Kumar N: Enhanced malaria parasite transmission from helminth co-infected mice. Am J Trop Med Hyg 2007, 76:1052-1056.

68. Noland GS, Graczyk TK, Fried B, Fitzgerald EJ, Kumar N: Exacerbation of Plasmodium yoelii malaria in Echinostoma caproni infected mice and abatement through anthelmintic treatment. J Parasitol 2005, 91:944-948.

69. Yan Y, Inuo G, Akao N, Tsukidate S, Fujita K: Down-regulation of murine susceptibility to cerebral malaria by inoculation with third-stage larvae of the filarial nematode Brugia pahangi. Parasitology 1997, 114:333-338. 
70. Fernandez Ruiz D, Dubben B, Saeftel M, Endl E, Deininger S, Hoerauf A, Specht S: Filarial infection induces protection against P. berghei liver stages in mice. Microbes Infect 2009, 11:172-180.

71. Specht S, Ruiz DF, Dubben B, Deininger S, Hoerauf A: Filaria-induced IL-10 suppresses murine cerebral malaria. Microbes Infect 12:635-642.

72. Graham AL, Lamb TJ, Read AF, Allen JE: Malaria-filaria coinfection in mice makes malarial disease more severe unless filarial infection achieves patency. J Infect Dis 2005, 191:410-421.

doi:10.1186/1475-2875-10-259

Cite this article as: Nacher: Interactions between worms and malaria: Good worms or bad worms? Malaria Journal 2011 10:259.

Submit your next manuscript to BioMed Central and take full advantage of:

- Convenient online submission

- Thorough peer review

- No space constraints or color figure charges

- Immediate publication on acceptance

- Inclusion in PubMed, CAS, Scopus and Google Scholar

- Research which is freely available for redistribution

Submit your manuscript at www.biomedcentral.com/submit
C Biomed Central 